Conditio Judaica 36

Studien und Quellen zur deutsch-jüdischen Literatur- und Kulturgeschichte

Herausgegeben von Hans Otto Horch

in Verbindung mit Alfred Bodenheimer, Mark H. Gelber und Jakob Hessing 



\section{Bettina Riedmann}

\section{"Ich bin Jude, \\ Österreicher, Deutscher"}

Judentum in Arthur Schnitzlers

Tagebüchern und Briefen

Max Niemeyer Verlag

Tübingen 2002 
Die Deutsche Bibliothek - CIP-Einheitsaufnahme

\section{Riedmann, Bettina:}

"Ich bin Jude, Osterreicher, Deutscher : Judentum in Arthur Schnitzlers Tagebüchern und Briefen / Bettina Riedmann. - Tübingen: Niemeyer, 2002

(Conditio Judaica; 36)

\section{ISBN 3-484-65136-9 ISSN 0941-5866}

C Max Niemeyer Verlag GmbH, Tübingen 2002

Das Werk einschließlich aller seiner Teile ist urheberrechtlich geschützt. Jede Verwertung außerhalb der engen Grenzen des Urheberrechtsgesetzes ist ohne Zustimmung des Verlages unzulässig und strafbar. Das gilt insbesondere für Vervielfältigungen, Ubersetzungen, Mikroverfilmungen und die Einspeicherung und Verarbeitung in elektronischen Systemen. Printed in Germany.

Gedruckt auf alterungsbeständigem Papier.

Druck: AZ Druck und Datentechnik GmbH, Kempten

Einband: Nädele Verlags- und Industriebuchbinderei, Nehren 